\title{
Erectile Function in Cardiovascular Disease and Hypertension: the Role of Nebivolol
}

\author{
Athanasios Manolis $^{1^{*}}$ and Michael Doumas ${ }^{2}$ \\ ${ }^{1}$ Cardiology Department, Asclepeion General Hospital, Athens, Greece \\ ${ }^{2}$ Aristotle University of Thessaloniki, Greece
}

*Corresponding author: Athanasios Manolis, 41, Thassou street, 16672, Athens, Greece, Tel: +30 2108970477; Fax: +30 2108923209; E-mail: ajmanol@otenet.gr

Received date: May 11, 2016; Accepted date: May 30, 2016; Published date: June 06, 2016

Copyright: (C) 2016 Manolis A, et al. This is an open-access article distributed under the terms of the Creative Commons Attribution License, which permits unrestricted use, distribution and reproduction in any medium, provided the original author and source are credited.

\begin{abstract}
Beta blockers are used for the management of arterial hypertension and are gold standard treatment for coronary artery disease and heart failure, medical conditions that affect large numbers of older patients and are associated with very high morbidity and mortality rates.

Lifelong therapy in primary and secondary prevention (without and with established cardiovascular disease, respectively) is limited by low adherence to drugs which is accompanied by increased mortality. Drug adverse events and impaired quality of life are among the main causes of poor adherence to therapy. Erectile dysfunction is the 'prima ballerina' of drug-induced life quality impairment. Beta blockers exert detrimental effects on erectile function. In contrast, nebivolol (a third generation beta blocker with vasodilating properties and proven efficacy in patients with hypertension and heart failure) does not share the unfavourable effects of other beta blockers on erectile function due to increased nitric oxide bioavailability.

Therefore, Nebivolol represents an attractive option for patients with hypertension, heart failure, and other related diseases who need to be treated with beta blockers.
\end{abstract}

Keywords: Antihypertensive drugs; Antihypertensive therapy; Beta blockers; Erectile dysfunction; Hypertension; Nebivolol; PDE-5 inhibitors; Sexual dysfunction Abbreviations: ACE: AngiotensinConverting Enzyme; cGMP: Cyclic Guanosine MonoPhosphate ; MR NOED: Metoprolol vs Nebivolol Study of Erectile Dysfunction; PDE: Phosphodiesterase; PDE-1: Phosphodiesterase type 1; PDE-5: Phosphodiesterase type 5; PDE-6: Phosphodiesterase type 6; PDE-11: Phosphodiesterase type 11

\section{Background}

Cardiovascular disease is the leading cause of mortality worldwide. Arterial hypertension is a major cardiovascular risk factor, affects almost one third of the adult population and is associated with approximately 7.6 million deaths annually [1]. High blood pressure affects the human vasculature and results in functional and structural alterations of the vessels all over the body [2]. Erectile dysfunction is currently considered of vascular origin in the vast majority of cases in middle-aged and older individuals, due to diffuse atherosclerosis and functional abnormalities of the penile arteries [3]. It is therefore of no surprise that erectile dysfunction is highly prevalent in patients with cardiovascular risk factors (arterial hypertension, diabetes mellitus, obesity, dyslipidemia) or overt cardiovascular disease (coronary artery disease, heart failure, stroke), with rates ranging from $40 \%$ to $90 \%$ that are significantly greater than in individuals free of cardiovascular disease [4-8].

Erectile dysfunction remains under-reported, under-detected and under-treated, despite significant advances in the post phosphodiesterase (PDE) -5 inhibitors era [4,5]. The timely recognition and management of erectile dysfunction in patients with arterial hypertension, in patients with cardiovascular risk factors and in patients with cardiovascular disease is of utmost importance for several reasons [9-11]. Mainly, because erectile dysfunction frequently precedes coronary artery disease by 3-5 years and provides the opportunity to detect and appropriately manage asymptomatic heart disease, and because erectile dysfunction severely impairs the quality of life of patients and their sexual partners, which can be effectively and safely managed even in patients with cardiovascular disease.

\section{Discussion}

\section{Nebivolol}

Nebivolol is a third-generation beta blocker with vasorelaxing properties [12]. Vasodilatory actions are shared by some other beta blockers as well (carvedilol and labetalol), however these actions are due to concomitant alpha blockade. In contrast nebivolol results in vasodilatation due to increased nitric oxide bioavailability via a direct stimulatory effect on endothelial nitric oxide synthase [13-15].

Nebivolol possesses some additional attractive characteristics, since it is the most selective beta- 1 blocker available, has a long half-life and its trough-to-peak ratio is $90 \%$ [16].

Of major importance, nebivolol unlike traditional beta blockers does not exert detrimental effects on glycose homeostasis (deterioration of insulin sensitivity and increased risk for new-onset diabetes mellitus) [17] even in combination with diuretics [18], is effective in patients with endothelial dysfunction [19], has a superior effect on central aortic pressure and left ventricular wall thickness compared to other beta blockers [20-22], is more effective in patients 
with nitric-oxide sensitive hypertension such as in patients with autonomic failure [23], does not impair the walking ability in patients with symptomatic peripheral artery disease [24], exerts beneficial effects on small arteries and micro-circulation in hypertensive patients [25], restores functional sympatholysis in hypertensive patients [26], and stimulates platelet nitric oxide production thus exerting thromboprotective effects [27]. These characteristics differentiate nebivolol from most available beta blockers and render nebivolol a good and attractive candidate for the management of arterial hypertension and cardiovascular disease (Table 1).

\begin{tabular}{|c|c|c|}
\hline & $\begin{array}{c}\text { Traditional beta } \\
\text { blockers }\end{array}$ & Nebivolol \\
\hline Blood pressure reduction & + & + \\
\hline Cardiovascular event reduction & + & + \\
\hline Coronary artery disease prevention & + & + \\
\hline Coronary artery disease treatment & + & + \\
\hline Heart failure prevention & + & + \\
\hline Heart failure treatment & + & + \\
\hline Nitric oxide bioavailability & - & + \\
\hline Endothelial function & - & + \\
\hline Central blood pressure & - & + \\
\hline Target organ damage & - & + \\
\hline Peripheral artery disease & - & + \\
\hline Chronic obstructive pulmonary disease & - & + \\
\hline Glucose homeostasis & - & + \\
\hline New onset diabetes & - & + \\
\hline Adverse events - Adherence to therapy & - & + \\
\hline
\end{tabular}

Table 1: Differences between traditional beta blockers and nebivolol in cardiovascular and other disease conditions.

Several studies established the efficacy and safety of nebivolol for the management of arterial hypertension, as monotherapy or combined with other classes of antihypertensive drugs [28,29]. Recently, the fixed dose combination of nebivolol and valsartan was found effective and safe in a large clinical trial of more than 4,000 hypertensive patients [30]. Nebivolol use has been also tested and proven effective and tolerated in patients with heart failure [31-34].

\section{Antihypertensive drugs and erectile dysfunction}

The increased prevalence of erectile dysfunction in arterial hypertension and other cardiovascular disease conditions raises the question whether erectile dysfunction is the result of high blood pressure and atherosclerosis or antihypertensive drugs contribute to the appearance of erectile dysfunction [35-38]. Accumulating evidence indicates that hypertension per se results in structural and functional abnormalities of the penile tissue and subsequent erectile dysfunction $[3,6]$. In addition, several antihypertensive drugs may cause erectile dysfunction [10]. In summary, older antihypertensive agents (centrally acting drugs, spironolactone, thiazides, beta blockers) exert negative effects on erectile function, while newer antihypertensive agents have either neutral (ACE [Angiotensin-Converting Enzyme] -inhibitors, calcium antagonists) or even positive effects (angiotensin receptor blockers, nebivolol) [11].

A recent systematic analysis about the effects of antihypertensive drugs on erectile function confirmed that renin-angiotensin-system inhibitors (angiotensin receptor blockers and ACE-inhibitors) and calcium antagonists have no relevant or even a positive effect on erectile function, while diuretics and beta blockers may adversely influence erectile function with the notable exception of nebivolol [39].

\section{Beta blockers and erectile dysfunction}

Beta blockers represent a widely heterogeneous class of drugs used for the management of arterial hypertension and other cardiovascular disease conditions, including coronary heart disease and heart failure. Large variations in selectivity of beta- 1 and beta- 2 adrenergic receptor blockade, in intrinsic sympathetic activity, and in vasorelaxation exist, permitting practicing physicians the choice of the right beta blocker for the individual patient.

Accumulating evidence points towards a detrimental effect of beta blockers on erectile function [10,40]. The mechanisms underlying the negative effects are yet unclarified and might include interference with the hormonal milieu in the penile tissue, such as the sympathetic nervous system (a major player in the erection and ejaculation process), testosterone and luteinizing hormone.

The causal association between beta blockers and erectile dysfunction has been recently questioned by a study that reported a ten-fold increased detection of erectile dysfunction in patients taking atenolol and knowing its side effects compared to patients who were unaware of which drug they were given [41]. It was therefore suggested that erectile dysfunction induced by beta blockers is actually perceived and not real, due to a 'nocebo' effect. Although a 'nocebo' effect is observed in some patients, it represents the exception and not the rule. A wealth of evidence from experimental studies, observational studies and randomized clinical studies that will be described below, strongly indicates without any doubt that beta blockers exert detrimental effects on erectile function, with the notable exception of nebivolol which acts favorably on erectile function.

\section{Nebivolol versus the other beta blockers in hypertensive patients with erectile dysfunction}

A diversity of the effects of various beta blockers on erectile dysfunction has been suggested. Data from experimental, observational, and clinical studies point towards a detrimental effect of beta blockers on erectile function with the exception of nebivolol. Nebivolol in hypertensive patients not only does not exert a negative effect in clinical studies but seems to exert a positive effect on erectile function through enhanced nitric oxide bioavailability.

Data from experimental studies: Nebivolol exerts beneficial effects on the erectile tissue of experimental animals. In particular, nebivolol increases serum nitrite/nitrate concentration by 3 times and plasma cGMP (cyclic Guanosine MonoPhosphate) levels by 2.75 times, enhances the endothelium-dependent relaxation of isolated human corpus cavernosum and produces endothelium-dependent vasodilatation of human penile resistance arteries [42]. In diabetic rats with erectile dysfunction, it was found that nebivolol significantly 
improved the erectile response to electrical stimulation, while atenolol had similar results with placebo (vehicle-treated animals) [42].

Nebivolol activates endothelial nitric oxide synthase in the smooth muscle cells of penile corpus cavernosum tissue. It was found that nebivolol results in a significant increase of endothelial nitric oxide synthase activation and phosphorylation as well as nitric oxide liberation in murine erectile tissue, whereas metoprolol does not exert such effects [43].

Another experimental study in apolipoprotein E knockout mice revealed that endothelium-dependent relaxation of the corpora cavernosa improved significantly with nebivolol but not with metoprolol. Likewise, nebivolol use was associated with a significant decrease of superoxide anion production via lipid peroxidation, whereas metoprolol failed to exert such beneficial effects [44].

In another experimental study the effects of nebivolol were compared with amlodipine. Nebivolol anticipated the appearance of structural alterations in the penile tissue whereas amlodipine failed to exert similar actions [45]. In addition, nebivolol increased the expression of endothelial nitric oxide synthase achieving the levels found in normotensive rats.

The detrimental effects of beta blockers on the penile structure were also observed in two more experimental studies, one comparing candesartan with atenolol in hypertensive rats and the other comparing losartan and benazepril with atenolol and amlodipine in rats with chronic renal insufficiency via subtotal nephrectomy [46,47].

It is therefore apparent from the findings of experimental studies that nebivolol improves penile endothelial function and protects from the development of structural and functional alterations in the penile tissue, whereas other beta blockers do not exert these 'peno-protective' actions, therefore indicating an effect which is drug-specific and is not shared by other beta blockers.

Data from observational studies: Data from observational studies in patients with arterial hypertension strongly point towards betweenclass and within-class differences in the effects of antihypertensive therapy on erectile function, indicating that beta blockers are associated with erectile dysfunction and nebivolol represents the only exception in this rule.

An observational, cross-sectional study of 634 consecutive young and middle-aged subjects evaluated erectile function with different antihypertensive drug classes [48]. Erectile function scores were significantly lower with older antihypertensive agents (diuretics and beta-blockers) than with modern antihypertensive agents (calcium antagonists, ACE-inhibitors, angiotensin receptor blockers). Of note, similar results were observed in females in another observational cross-sectional study of 417 women [49].

A large, cross-sectional study of more than a thousand middle-aged and older high-risk hypertensive patients reported the effects of betablockers on erectile function [50]. Erectile dysfunction was highly prevalent (71\%) among users of beta blockers for at least 6 months and the dysfunction was of relatively high severity (16.1\% severe; $16.8 \%$ moderate; and $38.1 \%$ mild). The most important finding of the study however was the diversity of the effects on erectile function among beta blockers. Metoprolol and carvedilol use was associated with the highest prevalence of erectile dysfunction, while nebivolol use was associated with the lowest prevalence of erectile dysfunction, and the effects of atenolol and bisoprolol were in between. Of note, patients on nebivolol had higher scores in every aspect of the International Index of Erectile Function questionnaire compared to patients on any other beta blocker.

Data from clinical studies. Several clinical studies confirm the between-class and within class differences regarding the effects of antihypertensive treatment on erectile function. Relevant studies are of major clinical significance, since they provide meaningful evidence for the clinical management of patients with arterial hypertension.

Three small, randomized, double-blind clinical studies that were carefully designed and conducted to specifically evaluate the effects of antihypertensive therapy on erectile function uncovered the detrimental effects of beta blockers. It was found that the use of beta blockers (atenolol and carvedilol) worsened significantly the sexual activity of hypertensive patients compared with either placebo or drugs inhibiting the renin-angiotensin system [51-53].

Nebivolol non-unfavorable effects on erectile function were revealed in three small, randomized, double-blind clinical studies. The Metoprolol vs Nebivolol study of Erectile Dysfunction (MR NOED) was specifically designed to evaluate the effects of antihypertensive therapy on erectile function in hypertensive patients. The MR NOED study was a randomized, double-blind study comparing nebivolol (5 $\mathrm{mg}$ ) with metoprolol (95 mg) for 12 weeks in patients with mild hypertension [54]. Blood pressure reduction was similar with both drugs; however the effects of metoprolol and nebivolol on erectile function differed significantly: metoprolol was associated with detrimental effects on erectile function, while nebivolol was associated with improvements on sexual activity scores and other subscores of erectile function [54]. In a randomized, double-blind study of 131 middle-aged hypertensive men, the effects of nebivolol on sexual function were compared with the effects of atenolol with and without chlorthalidone. It was found that atenolol was associated with a significant reduction of successful sexual intercourses per month (from 7.0 at baseline to 3.7 after 3 months; $\mathrm{p}<0.01$ ), and the negative effects were further exaggerated when atenolol was combined with chlorthalidone (from 6.4 to 2.8 , respectively; $\mathrm{p}<0.01$ ). On the contrary, the number of successful intercourses per month remained unaffected during the 3-month treatment with nebivolol (from 6.4 to 6.0, respectively; p: not significant [55]. Another randomized double-blind study of 314 patients with arterial hypertension compared the effects of nebivolol versus losartan on life quality, including sexual function. It was found that there was no difference between the two groups regarding the effects of nebivolol and losartan on sexual function, suggesting that nebivolol does not share the detrimental effects of other beta blockers on sexual function [56].

Sexual function has been assessed in some large randomized studies as a secondary end-point. It has to be noted however that these older studies have significant limitations, mainly the assessment of erectile function with "primitive" methodology and not by validated questionnaires. Of equal importance, these studies were conducted at the pre-PDE-5 inhibitors era, a time at which erectile dysfunction was a taboo issue and patients were not willing to discuss sexuality.

\section{Switching beta blockers to nebivolol for hypertensive patients with erectile dysfunction}

The acknowledgement of a detrimental role of beta blockers on erectile function and the evidence pointing towards a beneficial role of nebivolol, generate the hypothesis that switching prior beta blocker therapy to nebivolol might have beneficial effects in hypertensive patients with erectile dysfunction. 
We have conducted an open, prospective study in 44 hypertensive patients with erectile dysfunction while receiving beta-blockers, and evaluated the effects of switching prior therapy to nebivolol $(5-10 \mathrm{mg})$ for 3 months. Erectile function was significantly improved in $68 \%$ of the patients and was even normalized in more than half of patients experiencing improvement [57]. It has to be noted however that this was a small, open study and the results need to be confirmed by larger, randomized clinical studies.

\section{PDE-5 inhibitors in hypertension as concomitant therapies}

PDE-5 inhibitors revolutionized the management of patients with erectile dysfunction and represent the cornerstone of proposed therapeutic algorithms by the American and the European Urological Association and the first-line treatment for almost all types of erectile dysfunction [58,59]. PDE-5 inhibitors increase the intracellular levels of cGMP through PDE-5 inhibition and thus enhance nitric oxide bioavailability in the penile tissue leading to penile erection [60]. Four PDE-5 inhibitors are currently EU-approved and are available in the European market (sildenafil, vardenafil, tadalafil, avanafil).

Avanafil is the latest PDE-5 inhibitor in the market and has two important characteristics: a very rapid onset of action and a higher specificity for PDE-5 [61]. Avanafil is efficacious within approximately 15 min of its administration, and successful sexual attempts may be obtained as early as $10 \mathrm{~min}$ after dosing [62]. The high specificity of avanafil for PDE-5 may minimize adverse events occurring by inhibition of other PDE isoenzymes (PDE-6, PDE-1, and PDE-11), and confer improved tolerability [63].

PDE-5 inhibitors possess vasodilating properties and result in small reductions of blood pressure (usually $2-4 \mathrm{mmHg}$ ). This mild hypotensive effect has been observed in hypertensive patients (treated and untreated), patients with overt cardiovascular disease, and patients with cardiovascular risk factors. PDE-5 inhibitors are very effective in the management of erectile dysfunction. The response rates are about $70 \%$, and are not significantly attenuated by the presence of either overt cardiovascular disease or the co-existence of traditional cardiovascular risk factors [64-67]. Equally important, the overall good cardiovascular safety profile of PDE-5 inhibitors is maintained in patients with either cardiovascular risk factors or overt cardiovascular disease [68-72].

Concerns have been raised regarding the safety of PDE-5 inhibitors in patients with arterial hypertension who are taking multiple antihypertensive drugs due to the risk of significant hypotension. It has been found however that PDE- 5 inhibitors can be used concomitantly even in patients on perplexed multidrug regime $[3,10]$. The only exceptions are nitrates and alpha blockers. Nitrates are contraindicated in patients taking PDE-5 inhibitors and can be safely administered 24 hours after sildenafil and vardenafil intake, and at least $48 \mathrm{~h}$ after tadalafil intake [58]. The hemodynamic effects of nitrates co-administered with avanafil seem to be shorter in duration than the ones observed with sildenafil [73]. The co-administration of PDE-5 inhibitors with a-blockers is no longer contra-indicated, and caution alone is recommended. Symptomatic clinically significant hypotension may be avoided through several manoeuvres, including drug dosing (half doses with careful up-titration) and time separation (6 hours).

Benefits beyond the management of erectile dysfunction may also occur in hypertensive patients using PDE-5 inhibitors. PDE-5 inhibitors are associated with substantially increased adherence to antihypertensive therapy [74]. Better blood pressure control has been also reported in a large study of more than 6,500 hypertensive patients [75], which was probably due to a more aggressive therapeutic strategy and decreased discontinuation rates.

In conclusion, all available PDE-5 inhibitors are effective and well tolerated drugs in the treatment of erectile dysfunction in patients with arterial hypertension and in patients with controlled and carefully monitored cardiovascular disease.

\section{PDE-5 inhibitors and nebivolol: experimental data}

Experimental data suggest a synergistic effect of PDE-5 inhibitors with nebivolol on human corpus cavernosum: nebivolol significantly augments sildenafil-induced elevation of plasma cGMP levels and relaxation of isolated human corpus cavernosum [42]. Moreover, erectile dysfunction was completely reversed with sildenafil in diabetic rats pre-treated with nebivolol $(112 \%$ for sildenafil plus nebivolol compared to $69.6 \%$ for sildenafil alone) [42]. Another recent experimental study evaluated the effects of nebivolol addition to PDE-5 inhibitors (sildenafil, vardenafil, and tadalafil) on the capacity of PDE-5 inhibitors to relax human corpus cavernosum and vasodilate human penile resistance arteries from organ donors without erectile dysfunction and diabetic patients with erectile dysfunction [76]. It was found that the addition of nebivolol significantly potentiated the vasorelaxant properties of PDE-5 inhibitors and enhanced the elevation of cGMP levels induced by PDE-5 inhibitors, pointing towards a synergistic effect of nebivolol with PDE-5 inhibitors on erectile mechanisms [76].

Concerns have been raised about the safety of this combination, since excessive nitric oxide bioavailability might cause hypotension. However, preliminary evidence does not support these concerns. Experimental data in isolated vessel rings of rat aorta revealed that both sildenafil and nebivolol induced vasodilatation as expected. However, sildenafil did not potentiate the vasodilatory capacity of nebivolol in the aorta [77]. The latter observation combined with the abovementioned findings about the effects of this combination in the penile tissue point towards a differential effect of the PDE-5 inhibitors and nebivolol combination in different vascular beds. The synergistic beneficial effects in the penile tissue are not accompanied by synergistic effects in the aorta, which might have resulted in hypotension.

Experimental evidence supports recent observational data: we have recently reported the safety of nebivolol and PDE-5 co-administration in 76 patients with arterial hypertension and erectile dysfunction [78]. No significant adverse effects were reported, suggesting that nebivolol may safely be combined with PDE-5 inhibitors in hypertensive patients, since the benefits in erectile dysfunction are not associated with concerns for excessive symptomatic hypotension. The efficacy and safety of this combination remains to be verified by large prospective trials.

\section{Perspectives}

A wealthy of evidence points towards detrimental effects of beta blockers on erectile function. The ability of nebivolol to increase nitric oxide bioavailability is unique among beta blockers. This unique property of nebivolol seems to prevent beta blocker-induced erectile dysfunction, which frequently occurs with other beta blockers but not with nebivolol. Therefore, nebivolol is useful for the management of patients with essential hypertension, for whom the treating physician 
opts to use beta blockers and maintenance of erectile function is of essence for the patient. In addition, nebivolol is useful in hypertensive patients with erectile dysfunction while on beta blockers, since switching of administered therapy to nebivolol might be associated with benefits on erectile function.

\section{Results}

Erectile dysfunction is commonly found in patients with arterial hypertension, cardiovascular risk factors and overt cardiovascular disease. The vast majority of available evidence unveils a detrimental role of beta blockers in erectile dysfunction. In contrast, experimental and clinical data strongly point towards a beneficial effect of nebivolol on erectile function via increased nitric oxide bioavailability. The properties of nebivolol in regards to erectile dysfunction in hypertensive patients are unique among beta-blockers, rendering nebivolol an attractive choice in patients who care about erectile function and need to be treated with beta blockers.

\section{Competing Interests}

The author(s) declare that they have no competing interests.

\section{Authors' Contributions}

AM conceived of and designed the study, checked for accuracy and critically revised the manuscript, and gave the final approval of the version to be published. MD drafted the manuscript and gave the final approval for publication.

Authors' information: AM is a former Board member of the European Society of Hypertension and is currently the Chairman of the Working Group for arrhythmias and hypertension of the European Society of Hypertension. MD is co-chairman of the Working Group for sexual dysfunction and hypertension of the European Society of Hypertension.

\section{Acknowledgements: None.}

\section{References}

1. Lawes CM, Vander Hoorn S, Rodgers A (2008) International Society of Hypertension. Global burden of blood-pressure-related disease 371: 1513-1518.

2. Mancia G, Fagard R, Narkiewicz K, Redón J, Zanchetti A, et al. (2013) ESH/ESC guidelines for the management of arterial hypertension. J Hypertens 31: 1281-1357.

3. Manolis A, Doumas M (2008) Sexual dysfunction: the 'prima ballerina' of hypertension-related quality-of-life complications. J Hypertens 26: 2074-2084.

4. Manolis A, Doumas M (2012) Antihypertensive treatment and sexual dysfunction. Curr Hypertens Rep 14: 285-292.

5. Manolis A, Doumas M (2009) Hypertension and sexual dysfunction. Arch Med Sci 5: S337-S350.

6. Douma S, Doumas M, Tsakiris A, Zamboulis C (2007) Male and female sexual dysfunction: Is hypertension an innocent bystander or a major contributor? Rev Bras Hypertens 14: 139-147.

7. Doumas M, Douma S (2006) Sexual dysfunction in essential hypertension: myth or reality? J Clin Hypertens (Greenwich) 8: 269-274.

8. Vlachopoulos C, Jackson G, Stefanadis C, Montorsi P (2013) Erectile dysfunction in the cardiovascular patient. Eur Heart J 34: 2034-2046.

9. Manolis AJ, Doumas M, Viigimaa M, Narkiewitz K (2007) Hypertension and sexual dysfunction. European Society of Hypertension Scientific Newsletter: Update on Hypertension Management 8.
10. Manolis AJ, Doumas M, Viigimaa M, Narkiewitz K (2011) Hypertension and sexual dysfunction. European Society of Hypertension Scientific Newsletter: Update on Hypertension Management 32.

11. Doumas M, Douma S (2006) The effect of antihypertensive drugs on erectile function: a proposed management algorithm. J Clin Hypertens 8: 359-364.

12. Munzel T, Gori T (2009) Nebivolol: the somewhat-different betaadrenergic receptor blocker. J Am Coll Cardiol 54: 1491-1499.

13. Ignarro LJ (2008) Different pharmacological properties of two enantiomers in a unique beta-blocker: nebivolol. Cardiovasc Ther 26: 115-134.

14. Gao Y, Vanhoutte PM (2012) Nebivolol: an endothelium-friendly selective $\beta 1$-adrenoceptor blocker. J Cardiovasc Pharmacol 59: 16-21.

15. Vanhoutte PM, Gao Y (2013) Beta blockers, nitric oxide, and cardiovascular disease. Curr Opin Pharmacol 13: 265-273.

16. Howlett JG (2014) Nebivolol: vasodilator properties and evidence for relevance in treatment of cardiovascular disease. Can J Cardiol 30: S29-37.

17. Ayers K, Byrne LM, DeMatteo A, Brown NJ (2012) Differential effects of nebivolol and metoprolol on insulin sensitivity and plasminogen activator inhibitor in the metabolic syndrome. Hypertension 59: 893-898.

18. Stears AJ, Woods SH, Watts MM, Burton TJ, Graggaber J, et al. (2012) A double-blind, placebo-controlled, crossover trial comparing the effects of amiloride and hydrochlorothiazide on glucose tolerance in patients with essential hypertension. Hypertension 59: 934-942.

19. Masoli O, Redruello M, Balino NP, Grynberg L, Sonia T, et al. (2008) Use of nebivolol for the treatment of endothelial dysfunction in patients with hypertension: the EDEN registry. J Cardiovasc Pharmacol 51: 202-207.

20. Kampus P, Serg M, Kals J, Zagura M, Muda P, et al. (2011) Differential effects of nebivolol and metoprolol on central aortic pressure and left ventricular wall thickness. Hypertension 57: 1122-1128.

21. Polonia J, Barbosa L, Silva JA, Bertoquini S (2010) Different patterns of peripheral versus central blood pressure in hypertensive patients treated with beta blockers either with or without vasodilator properties or with angiotensin receptor blockers. Blood Press Monit 15: 235-239.

22. Vinereanu D, Gherghinescu C, Ciobanu AO, Magda S, Niculescu N, et al. (2011) Reversal of subclinical left ventricular dysfunction by antihypertensive treatment: a prospective trial of nebivolol against metoprolol. J Hypertens 29: 809-817.

23. Okamoto LE, Gamboa A, Shibao CA, Arnold AC, Choi L, et al. (2014) Nebivolol, but not metoprolol, lowers blood pressure in nitric oxidesensitive human hypertension. Hypertension 64: 1241-1247.

24. Diehm C, Pittrow D, Lawall H (2011) Effect of nebivolol vs. hydrochlorothiazide on the walking capacity in hypertensive patients with intermittent claudication. J Hypertens 29: 1448-1456.

25. Arosio E, De Marchi S, Prior M, Zannoni M, Lechi A (2002) Effects of nebivolol and atenolol on small arteries and microcirculatory endothelium-dependent dilation in hypertensive patients undergoing isometric stress. J Hypertens 20: 1793-1797.

26. Price A, Raheja P, Wang Z, Arbique D, Adams-Huet B, et al. (2013) Differential effects of nebivolol versus metoprolol on functional sympatholysis in hypertensive patients. Hypertension 61: 1263-1269.

27. Momi S, Caracchini R, Falcinelli E, Evangelista S, Gresele P (2014) Stimulation of platelet nitric oxide production by nebivolol prevents thrombosis. Arterioscler Thromb Vasc Biol 34: 820-829.

28. Weiss RJ, Saunders E, Greathouse M (2011) Efficacy and tolerability of nebivolol in stage I-II hypertension: a pooled analysis of data from threerandomized, placebo-controlled monotherapy trials. Clin Ther 33: 1150-1161.

29. Van Bortel LM, Fici F, Mascagni F (2008) Efficacy and tolerability of nebivolol compared with other antihypertensive drugs: a meta-analysis. Am J Cardiovasc Drugs 8: 35-44.

30. Giles TD, Weber MA, Basile J, Gradman AH, Bharucha DB, et al. (2014) Efficacy and safety of nebivolol and valsartan as fixed-dose combination in hypertension: a randomised, multicentre study. Lancet 383: 1889-1898. 
31. Conraads VM, Metra M, Kamp O, De Keulenaer GW, Pieske B, et al. (2012) Effects of long-term administration of nebivolol on the clinical symptoms, exercise capacity, and left ventricular function of patients with diastolic dysfunction: results of the ELANDO study. Eur J Heart Fail 14: 219-225.

32. Ambrosio G, Flather MD, Bohm M, Cohen-Solal A, Murrone A, et al. (2011) $\beta$-blockade with nebivolol for prevention of acute ischaemic events in elderly patients with heart failure. Heart 97: 209-214.

33. Flather MD, Shibata MC, Coats AJ, Van Veldhuisen DJ, Parkhomenko A, et al. (2005) Randomized trial to determine the effect of nebivolol on mortality and cardiovascular hospital admission in elderly patients with heart failure (SENIORS). Eur Heart J 26: 215-225.

34. van Veldhuisen DJ, Cohen-Solal A, Bohm M, Anker SD, Babalis D, et al. (2009) Beta-blockade with nebivolol in elderly heart failure patients with impaired and preserved left ventricular ejection fraction: Data From SENIORS (Study of Effects of Nebivolol Intervention on Outcomes and Rehospitalization in Seniors With Heart Failure). J Am Coll Cardiol 53: 2150-2158.

35. Viigimaa M, Vlachopoulos C, Lazaridis A, Doumas M (2014) Management of erectile dysfunction in hypertension: Tips and tricks. World J Cardiol 6: 908-915.

36. Doumas M, Viigimaa M, Papademetriou V (2013) Combined antihypertensive therapy and sexual dysfunction: terra incognita. Cardiology 125: 232-234.

37. Viigimaa M, Lazaridis A, Doumas M (2012) Management of sexual dysfunction in hypertensive patients. Cardiol Clin Practice 4: 53-60.

38. Viigimaa M, Doumas M, Vlachopoulos C, Anyfanti P, Wolf J, et al. (2011) European Society of Hypertension Working Group on Sexual Dysfunction. Hypertension and sexual dysfunction: time to act. J Hypertens 29: 403-407.

39. Baumhakel M, Schlimmer N, Kratz M, Hackett G, Jackson G, et al. (2011) Cardiovascular risk, drugs and erectile function--a systematic analysis. Int J Clin Pract 65: 289-298.

40. Douma S, Doumas M, Petidis K, Triantafyllou A, Zamboulis C (2008) Beta blockers and sexual dysfunction: bad guys - good guys. In: Beta Blockers: New Research - editors: Momoka Endo and Narami Matsumoto. Nova Science Publishers Inc 1-13.

41. Silvestri A, Galetta P, Cerquetani E, Marazzi G, Patrizi R, et al. (2003) Report of erectile dysfunction after therapy with beta-blockers is related to patient knowledge of side effects and is reversed by placebo. Eur Heart J 24: 1928-1932.

42. Angulo J, Wright HM, Cuevas P, Gonzalez-Corrochano R, Fernández A, et al. (2010) Nebivolol dilates human penile arteries and reverses erectile dysfunction in diabetic rats through enhancement of nitric oxide signalling. J Sex Med 7: 2681-2697.

43. Reidenbach C, Schwinger RH, Steinritz D, Kehe K, Thiermann H, et al. (2007) Nebivolol induces eNOS activation and NO-liberation in murine corpus cavernosum. Life Sci 80: 2421-2427.

44. Baumhakel M, Schlimmer N, Buyukafsar K, Arikan O, Bohm M (2008) Nebivolol, but not metoprolol, improves endothelial function of the corpus cavernosum in apolipoprotein e-knockout mice. J Pharmacol Exp Ther 325: 818-823.

45. Toblli JE, Cao G, Casas G, Mazza ON (2006) In vivo and in vitro effects of nebivolol on penile structures in hypertensive rats. Am J Hypertens 19: 1226-1232.

46. Toblli J, Stella I, Nestor Mazza O, Ferder L, Inserra F (2004) Protection of cavernous tissue in male spontaneously hypertensive rats. Beyond blood pressure control. Am J Hypertens 17: 516-522.

47. Toblli JE, Stella I, Mazza ON, Ferder L, Inserra F (2006) The effect of different antihypertensive drugs on cavernous tissue in experimental chronic renal insufficiency. J Nephrol 19: 419-428.

48. Doumas M, Tsakiris A, Douma S, Grigorakis A, Papadopoulos A, et al. (2006) Factors affecting the increased prevalence of erectile dysfunction in Greek hypertensive compared with normotensive subjects. J Androl 27: 469-477.
49. Doumas M, Tsiodras S, Tsakiris A, Douma S, Chounta A, et al. (2006) Female sexual dysfunction in essential hypertension: a common problem being uncovered. J Hypertens 24: 2387-2392.

50. Cordero A, Bertomeu-Martínez V, Mazon P, Facila L, Bertomeu-Gonzalez $\mathrm{V}$, et al. (2010) Erectile dysfunction in high-risk hypertensive patients treated with beta-blockers agents. Cardiovascular Therapeutics 28: 15-22.

51. Fogari R, Zoppi A, Corradi L, Mugellini A, Poletti L, et al. (1998) Sexual function in hypertensive males treated with lisinopril or atenolol: a crossover study. Am J Hypertens 11: 1244-1247.

52. Fogari R, Zoppi A, Poletti L, Marasi G, Mugellini A, et al. (2001) Sexual activity in hypertensive men treated with valsartan or carvedilol: a crossover study. Am J Hypertens 14: 27-31.

53. Fogari R, Preti P, Derosa G, Marasi G, Zoppi A, et al. (2002) Effect of antihypertensive treatment with valsartan or atenolol on sexual activity and plasma testosterone in hypertensive men. Eur J Clin Pharmacol 58: 177-180.

54. Brixius K, Middeke M, Lichtenthal A, Jahn E, Schwinger RH (2007) Nitric oxide, erectile dysfunction and beta-blocker treatment (MR NOED study): benefit of nebivolol versus metoprolol in hypertensive men. Clin Exp Pharmacol Physiol 34:327-31.

55. Boydak B, Nalbantgil S, Fici F, Nalbantgil I, Zoghi M, et al. (2005) A Randomised Comparison of the Effects of Nebivolol and Atenolol with and without Chlorthalidone on the Sexual Function of Hypertensive Men. Clin Drug Investig 25: 409-416.

56. Van Bortel LM, Bulpitt CJ, Fici F (2005) Quality of life and antihypertensive effect with nebivolol and losartan. Am J Hypertens 18: 1060-1066.

57. Doumas M, Tsakiris A, Douma S, Grigorakis A, Papadopoulos A, et al. (2006) Beneficial effects of switching from beta-blockers to nebivolol on the erectile function of hypertensive patients. Asian J Androl 8: 177-182.

58. Hatzimouratidis K (2015) Reply to Pero Bokarica's letter to the editor re: K. Hatzimouratidis, I. Eardley, F. Giuliano, I. Moncada, A. Salonia. Guidelines on male sexual dysfunction: erectile dysfunction and premature ejaculation. European Association of Urology Eur Urol 68: e78.

59. Montague DK, Jarow JP, Broderick GA, Dmochowski RR, Heaton JP, et al. (2005) The management of erectile dysfunction: an AUA update. J Urol 174: 230-239.

60. Chrysant SG, Chrysant GS (2012) The pleiotropic effects of phosphodiesterase 5 inhibitors on function and safety in patients with cardiovascular disease and hypertension. J Clin Hypertens (Greenwich) 14: 644-649.

61. Wang H, Yuan J, Hu X, Tao K, Liu J, et al. (2014) The effectiveness and safety of avanafil for erectile dysfunction: a systematic review and metaanalysis. Curr Med Res Opin 30: 1565-1571.

62. Hellstrom WJ, Kaminetsky J, Belkoff LH, Goldstein I, Tursi JP, et al. (2015) Efficacy of avanafil 15 minutes after dosing in men with erectile dysfunction: a randomized, double-blind, placebo controlled study. J Urol 194: 485-492.

63. Wang R, Burnett AL, Heller WH, Omori K, Kotera J, et al. (2012) Selectivity of avanafil, a PDE5 inhibitor for the treatment of erectile dysfunction: implications for clinical safety and improved tolerability. J Sex Med 9: 2122-2129.

64. Conti CR, Pepine CJ, Sweeney M (1999) Efficacy and safety of sildenafil citrate in the treatment of erectile dysfunction in patients with ischemic heart disease. Am J Cardiol 83: 29C-34C.

65. DeBusk RF, Pepine CJ, Glasser DB, Shpilsky A, DeRiesthal H, et al. (2004) Efficacy and safety of sildenafil citrate in men with erectile dysfunction and stable coronary artery disease. Am J Cardiol 93: 147-153.

66. Katz SD, Parker JD, Glasser DB, Bank AJ, Sherman N, et al. (2005) Efficacy and safety of sildenafil citrate in men with erectile dysfunction and chronic heart failure. Am J Cardiol 95: 36-42.

67. Nehra A (2009) Erectile dysfunction and cardiovascular disease: efficacy and safety of phosphodiesterase type 5 inhibitors in men with both conditions. Mayo Clin Proc 84: 139-148. 
Citation: Manolis A, Doumas M (2016) Erectile Function in Cardiovascular Disease and Hypertension: the Role of Nebivolol . J Hypertens 5: 226.

68. Stuckey BG, Jadzinsky MN, Murphy LJ, Montorsi F, Kadioglu A, et al. (2003) Sildenafil citrate for treatment of erectile dysfunction in men with type 1 diabetes: results of a randomized controlled trial. Diabetes Care 26: 279-284.

69. Boulton AJ, Selam JL, Sweeney M, Ziegler D (2001) Sildenafil citrate for the treatment of erectile dysfunction in men with Type II diabetes mellitus. Diabetologia 44: 1296-1301.

70. Buranakitjaroen P, Mangklabruks A, Leungwattanakij S, Ngaothamatasn W, Malhotra C, et al. (2007) Efficacy and safety of sildenafil in Asian males with erectile dysfunction and cardiovascular risk. J Med Assoc Thai 90: 1100-1108.

71. Pickering TG, Shepherd AM, Puddey I, Glasser DB, Orazem J, et al (2004) Sildenafil citrate for erectile dysfunction in men receiving multiple antihypertensive agents: a randomized controlled trial. Am J Hypertens 17: 1135-1142.

72. Olsson AM, Persson CA (2001) Swedish Sildenafil Investigators Group Efficacy and safety of sildenafil citrate for the treatment of erectile dysfunction in men with cardiovascular disease. Int J Clin Pract 55: 171-176.

73. Swearingen D, Nehra A, Morelos S, Peterson CA (2013) Hemodynamic effect of avanafil and glyceryl trinitrate coadministration. Drugs Context 2013: 212248 .
74. McLaughlin T, Harnett J, Burhani S, Scott B (2005) Evaluation of erectile dysfunction therapy in patients previously nonadherent to long-term medications: a retrospective analysis of prescription claims. Am J Ther 12: 605-611.

75. Scranton RE, Lawler E, Botteman M, Chittamooru S, Gagnon D, et al. (2007) Effect of treating erectile dysfunction on management of systolic hypertension. Am J Cardiol 100: 459-463.

76. Martínez-Salamanca JI, La Fuente JM, Cardoso J, Fernández A, Cuevas P, et al. (2014) Nebivolol potentiates the efficacy of PDE5 inhibitors to relax corpus cavernosum and penile arteries from diabetic patients by enhancing the NO/cGMP pathway. J Sex Med 11: 1182-1192.

77. Rosenkranz S, Brixius K, Halbach R, Diedrichs H, Schwinger RH (2006) Phosphodiesterase type 5 inhibitor sildenafil citrate does not potentiate the vasodilative properties of nebivolol in rat aorta. Life Sci 78: 1103-1107.

78. Lazaridis A, Reklou A, Doumas M (2013) Safety of nebivolol and PDE-5 inhibitors co-administration in hypertensive patients with sexual dysfunction. J Hypertens 31(Suppl A): e464. 